Europe's Journal of Psychology, 6(3), pp. 122-148

www.ejop.org

\title{
Does Humor Benefit Health In Retirement? Exploring Humor as a Moderator
}

\author{
Gillian P. Freeman
}

The University of Massachusetts Amherst, United States of America

W. Larry Ventis

The College of William \& Mary, United States of America

\begin{abstract}
This research assessed the extent to which humor moderates the relationship between retirement stress, including hassles, and health. Two hundred sixty-five retirees over the age of 55 years responded to an on-line survey, completing the RAND 36-ltem Health Survey and the Humor Styles Questionnaire. Stress was measured using the Self Perceived Stress in Retirement Scale and The Hassles Scale. The stress moderating effect of humor was examined via regression analyses. Contrary to expectation, and the assumed nature of humor styles, results suggest that the adaptiveness of humor styles depends on the level of stress or hassles one perceives, as well as gender. This is a first indication that whether specific humor styles are adaptive or maladaptive may depend on specific circumstances or person variables.
\end{abstract}

Keywords - humor, retirement, coping, stress, health

Both researchers and the popular media alike have taken an increased interest in individuals' adaptation to retirement (Beehr \& Adams, 2003). Successful adaptation to retirement involves coping with changes in income, social supports, and the loss of work identity and alterations in general identity (Hayslip, Beyerlein, \& Nichols, 1997; Sharpley, 1997). While many are able to transition into retirement with little problem, for a large number of people, the retirement transition is disruptive and a period of instability (Marshall, Clarke, \& Ballantyne, 2001). Thus the aim of the current study was to better understand how the four humor styles, identified by the Humor Styles Questionnaire (HSQ; Martin, Puhlik-Doris, Larsen, Gray, \& Weir, 2003), are associated 
with perceived retirement stress and daily life hassles. These four styles include two positive or adaptive humor styles (Affiliative humor and Self-enhancing humor) and two negative humor or maladaptive humor styles (Aggressive humor and Selfdefeating humor). To our knowledge this is the first research to investigate coping humor and the humor styles among retirees.

In the current investigation, physical and mental health outcomes were assessed as well, to explore how humor moderates the relationship between health and stress during retirement.

Humor, Health, and Stress

There exists substantial literature that suggests that life stress is detrimental to physical and psychological wellbeing (Cohen, Janicki-Deverts, \& Miller, 2007; Gunnar \& Quevedo, 2007; Miller, Chen, \& Zhou, 2007). Together this body of research underscores the relationship between stress and poor health among various agegroups.

A recent study that examined the stress and health relationship among an aging sample found individual differences in self-perceived stress and health outcomes in older adults (Sapolsky, 2004). Sapolsky (2004) reported that although some individuals with significant chronic stress appear to be coping well, many are not and experience negative changes in lifestyle and health impairments due to chronic stress.

In the present study, we examined to what extent one particular coping mechanism, humor, may be adaptive in buffering the stress and health relationship. It has now been acknowledged that humor is a multi-dimensional construct (Kuiper, Grimshaw, Leite, \& Kirsh, 2004; Thorson \& Powell, 1993) involving cognitive, emotional, behavioral, physiological, and social aspects (Martin, 2007). In observation of the multidimensionality of humor, a more recent shift in humor research has been to investigate both its possible beneficial and deleterious impact on health and wellbeing (Kirsh \& Kuiper, 2003; Kuiper et al., 2004; Tümkaya, 2007). The development of the Humor Styles Questionnaire (HSQ) has advanced humor research, as it assesses individual differences in the four styles of humor along what are believed to be both beneficial and deleterious dimensions of humor (Martin et al., 2003). The HSQ assesses four distinct and independent dimensions of humor-two dimensions of humor are typically positively related to health and well-being and two dimensions are typic ally negativ ely related to health and well-being. 
Martin and his colleagues (2003) identified two uses of humor they endorse as being potentially adaptive. These uses of humor include Affiliative humor, which involves the use of humor to enhance one's relationships with others, and Self-enhancing humor, which involves the use of humor to enhance the self and find humor in stressful situations (Martin et al., 2003). In addition, Martin and colleagues have identified two humor styles they propose to be detrimental or maladaptive uses of humor. These maladaptive styles have been identified as Aggressive humor and Selfdefeating humor (Martin et al., 2003). Aggressive humor is the use of humor to enhance the self at the expense of others, while Self-defeating humor is the use of humor to enhance relationships at the expense of self (Martin et al., 2003). Selfdefeating humor relates to tendencies to use humor in an excessively selfdisparaging and ingratiating way, and the use of humor as a form of defensive denial to hide underlying negative feelings (Martin et al., 2003).

It is often assumed that humor benefits both physical and psychological health, however, research thus far has yielded equivocal results (see Kuiper et al., 2004; Martin, 2004; Nezu, Nezu, \& Blissett, 1988). It has been suggested that the diverse conceptualizations of both humor and well-being account for much of the confusion in comparing results across studies (Martin, 2004). Nonetheless, humor does appear to have physiological benefits, which may be especially important to the well-being of older, more sedentary adults who can benefit from the increases in circulation and immune function brought about by laughter (Berk, 2001).

Humor and Stress During Retirement

A possible explanation for contradicting results in coping humor research is that coping, like humor, is a multidimensional construct (Carver, Scheier, \& Weintraub, 1989; Folkman \& Lazarus, 1988). Previous research may have assessed coping hu mor over a range, not only of humor measures but also of coping situations as well, making comparisons across studies inappropriate.

For this reason we examined the effects of humor styles, especially coping humor, during a specific period of stress-retirement. Increases in health problems and many other types of stress related to aging, such as losses of friends, family, health, and mobility, are characteristic of retirement (Aldwin, Yancura, \& Boeninger, 2007).

Coping responses are among the many predictors of adaptation to retirement including personal characteristics, and financial, social, and physical resources before and after retirement (Pinquart \& Schindler, 2007; Wang, 2007). It has been suggested that humor may be a positive means of coping with age-related loss 
(Simon, 1988, as cited in Celso et al., 2003). Folkman, Lazarus, Pimley, and Novacek (1987) found that emotion-focused forms of coping (including humor) are useful strategies for older adults who perceive stressful events as out of their control. Given that retirement and aging mean giving up control and autonomy in some cases (Kelly \& Barratt, 2007), humor may be one of the more useful coping strategies during this time period.

Humor as a Moderator

It has been proposed that there are three possible mechanisms by which humor and laughter impact physical health. First, it has been suggested that the laughter that accompanies humor conveys beneficial physiological changes in neural, muscoskeletal, cardiovascular, endocrine, and/or immunological systems (see Berk, 2001). Second, laughter and humor may directly affect health via their accompanying positive emotional states (Argyle, 1997; Edwards \& Cooper, 1988). Third, it has been posited that humor may moderate the relationship between stress and health. It has been proposed that changes in cognitive appraisals and attributions, as a result of a humorous outlook on life, may lead to more positive coping strategies, reduce stress, and improve health (Martin, Kuiper, Olinger, \& Dance, 1993). In this perspective humor has an indirect, rather than direct, effect on physiological health variables-interacting with stress levels in reducing the degree to which stress would normally negatively affect health.

It is the stress-moderating theory that was examined in the current study. A humorous perspective on an otherwise stressful situation may serve as an adaptive coping strategy similar to positive reinterpretation or perspective-taking (Kuiper, Martin, \& Olinger, 1993; Lefcourt, Davidson, Shepherd, Phillips, Prkachin, \& Mills, 1995). In this view it is the cognitive component of humor, rather than the physiological products of laughter, that is associated with the use of humor as a coping strategy (Kuiper et al., 1993).

The examination of humor as a moderator also introduces the possibility that certain styles and uses of humor may be more adaptive and health enhancing, whereas others are maladaptive (Martin, 2001). Examining the four humor styles proposed by Martin et al. (2003), in terms of a stress-moderating perspective, one can imagine Aggressive humor could serve as an avoidance or defense mechanism that may be less conducive to effective coping with stress than a Self-enhancing approach. Affiliative humor could be used to enhance social support that is more beneficial to coping than utilizing a defensive denial strategy with Self-defeating humor. 
Thus far, studies specifically investigating the stress moderating effect of humor have produced weak and inconsistent results. Research has found that depressive reactions to stress were mitigated in those who employed humor as a coping strategy (Nezu et al., 1988). However, other studies examining the relationship between humor and well-being have not found any effect (Boyle \& Joss-Reid, 2004; Porterfield, 1987) or have found significant results suggesting that humor has a detrimental effect on coping (Anderson \& Arnoult, 1989). It has been suggested that previous use of unidimensional instruments to measure humor accounts for the weak results (Boyle \& Joss-Reid, 2004), and diverse conceptualizations of both humor and well-being account for some of these inconsistencies between studies (Martin, 2004).

This study was an attempt to reconcile these inconsistencies in two ways. First, by utilizing the HSQ (Martin et al., 2003), we examined two positive and two negative styles of humor. By examining two seemingly adaptive humor styles and two seemingly maladaptive humor styles, we hoped to better understand both the positive and negative implications of humor styles in relation to stress during retirement.

Second, we examined the stress-moderating theory during a specific period of stress-retirement. In particular, we examined humor styles in relation to stress measures both proximal (hassle intensity) and distal (global retirement-specific stress) to the occurrence of humor among retirees. Specifically regarding the stress measures, we used those that tapped into perceived stress, rather than stressors. This is particularly relevant with hassles, where perception is part of determining whether something is labeled as a hassle, and if so, with what intensity. Likewise, with the global retirement stress, perceived stress during retire ment was measured.

In the stress literature, proximal measures of stress refer to those that capture an individual's immediate perception and life situation, whereas distal measures of stress typically do not describe the ongoing, immediate, pressures of life (DeLongis, Coyne, Dakof, Folkman, \& Lazarus, 1982). In this way Lazarus and colleagues have proposed that daily hassles are proximal measures of stress because they pertain to a person's immediate life circumstances (DeLongis et al., 1982). Measures of global retirement stress perception, like life events, on the other hand, are more distal to the immediate life circumstance (DeLongiset al., 1982; Rowlinson \& Felner, 1988).

\section{Gender Differences}

In studies that examined the relationship between stress and health reporting numerous individual differences, gender has been reported to affect both stress 
perception and resulting coping behaviors. Numerous reports suggest that females report being in more stressful situations and have more chronic stress than males (Matud, 2004; McDonough \& Walters, 2001). It has been suggested that traditional gender-roles may play a role in stress and coping differences as females typically serve as caregivers (Lee, 2001), may be more emotionally involved than males in social and family interactions (Kessler \& McLeod, 1984), and experience more daily demands and frustrations (Matud, 2004).

Gender differences in health have also been consistently reported among older adults. There is a significant difference in mortality rates as women live about 6-8 years longer than men (WHO, 2000). Although women live longer, they also have higher morbidity rates compared to men their own age. This paradox of a lower mortality rate and higher impairments in mobility and functioning has been frequently reported (see Arber \& Cooper, 1999). It has been suggested that gender differences in self-reported health may be the cause of reported disparities. However, a recent study gathered self-reported health data via interview of a sample of 544 community-dwelling participants over the age of 65 . They found that gender differences were due to a worse health status of women, rather than to differences in self-reports (Orfila, Ferrer, Lamarca, Tebe, Domingo-Salvany, \& Alonso, 2006).

Research examining humor as a moderator between stress and health have either not found or not reported gender differences (Anderson \& Arnoult, 1989; Boyle \& Joss-Reid, 2004; Nezu et al., 1988; Porterfield, 1987). However, some gender differences have been found in the use of humor. Studies utilizing the HSQ have found that males report using both Aggressive and Self-defeating humor styles more often than females (Freeman \& Ventis, 2008, November; Kazarian \& Martin, 2004; Martin et al., 2003) or have found no gender differences at all (Erickson \& Feldstein, 2007). In addition, studies have not reported any gender differences in coping humor scores (Anderson \& Arnoult, 1989; Nezu et al., 1988).

Because gender appears to affect stress, health, and humor measures, it may be worthw hile to explore if humor moderates the relationship between stress and health differently for males and females.

Aims of Current Study

In summary, this study sought to broaden the depth of knowledge of both humor and retirement stress by clarifying the stress-moderating theory of humor on health. First, it was hypothesized that the two adaptive humor styles, especially Self- 
enhancing humor, would be negatively correlated with stress and poor health. Second, we expected that the two maladaptive humor styles would be positively correlated with stress and poor health. Finally, it was expected that humor styles would act as a moderator of stress that is both proximal to humor (daily hassles) and stress that is more distal (retirement stress) on overall health. Specifically, adaptive humor styles were expected to boost health scores, especially during periods of high stress or high hassles (as opposed to low stress or low hassles). On the other hand, maladaptive humor styles were expected to have the opposite effect. Reports of high use of negative humor styles were expected to diminish positive health outcomes, especially during periods of high stress.

Exploratory analysis was conducted on gender differences. Given that females experience more daily hassles and have a higher rate of morbidity than males, it was expected that the specific stress and health relationship that is mo derated by humor may differ depending on gender.

\section{Method}

Participants

With the help of the College of William \& Mary's Alumni Association, approximately 5900 William \& Mary alumni who graduated prior to 1976 were invited to complete an online survey if they were both over the age of 55 and retired. The survey site was visited 674 times following the email invitation. Of the 674 site visits, 323 individuals consented (351 site visits did not result in participation). Of the 323 consenting participants, 10 surveys were incomplete and 48 individuals were not retired, leaving a final sample size of 265 retired adults ranging from $55-91$ years of age. The mean age of the sample is 67.48 years (SD $=7.293$ ). One hundred and twenty-one $(45.7 \%)$ participants were female and $143(54.0 \%)$ were male and one respondent $(.4 \%)$ did not specify a gender. The mean age of males $w$ as 68.99 years (SD $=7.074$ ) and the mean age of females was $65.58(S D=6.989)$.

This sample is predominantly Caucasian ( $n=260,98.1 \%$ ). One participant represented Multiple Ethnicity $(0.4 \%)$, and four respondents did not provide ethnicity information (1.5\%).

Due to the manner of recruitment, this sample was highly educated. Nearly half of the respondents had completed masters-level degrees ( $n=113,42.6 \%$ ). The second highest degree attained was 4-year college degree ( $n=103,38.9 \%$ ), followed by doctorate $(n=47,17.7 \%)$ and 2 -year college degree $(n=2,0.8 \%)$. 
Humor Styles Questionnaire (HSQ; Martin, Phulik-Doris, Larsen, Gray \& Weir, 2003). The $H S Q$ is a 32-item questionnaire that assesses four different styles of humor. Respondents indicate on a seven-point Likert scale the degree to which they agree or disagree with each item. Self-enhancing and Affiliative humor styles were identified as two facilitative humor styles and Aggressive and Self-defeating humor styles were identified as the two deleterious styles. The Self-enhancing dimension involves the use of humor as a coping mechanism. Items assessing each of the humor styles follow: "If I'm by myself and I'm feeling unhappy, I make an effort to think of something funny to cheer myself up" (Self-enhancing); "I laugh and joke a lot with my friends" (Affiliative); "I let people laugh at me or make fun at my expense more than I should" (Self-defeating); "If I don't like someone, I often use humor or teasing to put them down" (Aggressive). The test-retest correlations are: 0.81 for Selfenhancing humor; 0.85 for Affiliative humor; 0.82 for Self-defeating humor; and 0.80 for Aggressive humor (Martin et al., 2003). In the present sample, internal consistencies (Cronbach's $\alpha$ ) for the Self-enhancing, Affiliative, Self-defeating, and Aggressive humor scales were $0.80,0.86,0.80$, and 0.75 , respectively.

Daily Hassles Scale (Kanner, Coyne, Schaefer \& Lazarus, 1981).

The Hassles scale measures the occurrence and intensity of 117 hassles that characterize everyday dealings with the environment. Daily hassles include: "inconsiderate smokers," "filling out forms," and "troublesome neighbors". Circling the hassle indicates occurrence of hassles. Intensity is measured on a three-point scale ranging from 1 (somewhat severe) to 3 (extremely severe). This scale provides an easy way to demonstrate an individual's need to cope. The test-retest correlation is 0.48 for hassles intensity (Kanner et al., 1981). The internal consistency coefficient (Cronbach's $\alpha$ ) was .95 for the present study.

Self-Perceived Stress in Retirement Scale (Sharpley, 1997).

The Self-perceived Stress in Retirement Scale measures the amount of stress a retiree experiences on a day-to-day basis. The scale presents 14 items including "Your physical health," "Loss of purpose," and "Boredom," which are rated on a five-point scale ranging from 1 (little to no stress) to 5 (extreme stress). For the present study, the internal consistency coefficient (Cronbach's $\alpha$ ) was 0.80 .

RAND 36-Item Short Form Health Survey (SF-36; Hays, Sherbourne, \& Mazel, 1993). The SF-36 is a 36-item survey that assesses both physical and mental health. Each item is scored on a 0 to 100 range so that the higher number represents a more favorable health state. Items intended to measure physical health include: physical 
functioning, pain, general health, and role limitations due to physical problems. Items designed to measure mental health include: energy/vitality, social functioning, emotional wellbeing, and role limitations due to emotional problems. Many psychometric analyses have been published on the SF-36 reporting good reliability and validity. The internal consistency coefficients (Cronbach's $\alpha$ ) for the present study ranged from 0.70 to 0.89 .

\section{Demographics.}

Items concerned general background information (e.g., gender and ethnicity) as well as the respondent's pre-retirement income.

\section{Procedure}

In this correlational study, all self-report surveys were uploaded onto Opinio's online survey software. The survey took approximately 45 minutes to answer. Participants were encouraged to complete the survey independently, in a quiet location.

\section{Results}

Initial Analysis

Means and standard deviations of the humor, stress, and health measures for the entire sample, as well as for females and males separately, are presented on Table 1. Initial independent-measures t-tests revealed significant gender differences between means along humor, stress, and health variables. It is worth noting that, in this sample, significant correlations were not found between time since retirement and our variables of interest. First, analysis of the sample as a whole will be discussed, followed by the outcomes of gender differences.

\begin{tabular}{lccc}
\hline & Combined & Male & Female \\
& $M(S D)$ & $M(S D)$ & $M(S D)$ \\
\hline Affiliative humor* & $42.57(9.21)$ & $43.85(8.21)$ & $41.08(10.14)$ \\
Self-enhancing humor & $40.11(7.55)$ & $39.82(7.09)$ & $40.44(8.11)$ \\
Aggressive humor*** & $22.98(8.16)$ & $26.16(7.93)$ & $19.29(6.72)$ \\
Self-defeating humor** & $24.67(8.31)$ & $25.96(7.73)$ & $23.01(8.69)$ \\
Retirement Stress** & $21.84(5.73)$ & $21.00(5.09)$ & $22.83(6.29)$ \\
Hassles Intensity & $1.15(0.28)$ & $1.12(0.28)$ & $1.18(0.27)$ \\
General Health & $68.16(19.93)$ & $68.25(18.91)$ & $68.00(21.23)$ \\
Physical Functioning & $80.56(20.32)$ & $82.08(19.15)$ & $78.90(21.61)$
\end{tabular}




$\begin{array}{llll}\text { Role Limitations (Physical) } & 79.13(31.51) & 82.56(28.60) & 75.00(34.31) \\ \text { Role Limitations (Emotional) } & 88.95(24.25) & 89.55(22.69) & 88.15(26.13) \\ \text { Energy/Vitality } & 65.25(19.57) & 66.29(19.12) & 64.06(20.18) \\ \text { Social Functioning } & 91.18(16.98) & 92.31(15.62) & 89.77(18.47) \\ \text { Pain* } & 76.57(18.56) & 79.16(16.33) & 73.57(20.61) \\ \text { Emotional Wellbeing* } & 82.36(13.42) & 83.90(13.17) & 80.52(13.59)\end{array}$

Note. Asterisks after variable names indicate a significant gender difference, ${ }^{*} p<.05{ }^{* *} p<.01{ }^{* * *} p<.001$.

Table 1. Means and Standard Deviations for Humor, Stress, and Health Measures

Generally, the expected significant correlations between humor styles, stress, and health were found. The intercorrelations are presented in Table 2. Looking at the correlations between humor styles and stress, as expected, both adaptive humor styles had negative correlations with the stress measures Affiliative humor had a significant negative correlation with Hassles Intensity, but not Retirement Stress. Selfenhancing humor had significant negative correlations with both stress meas ures.

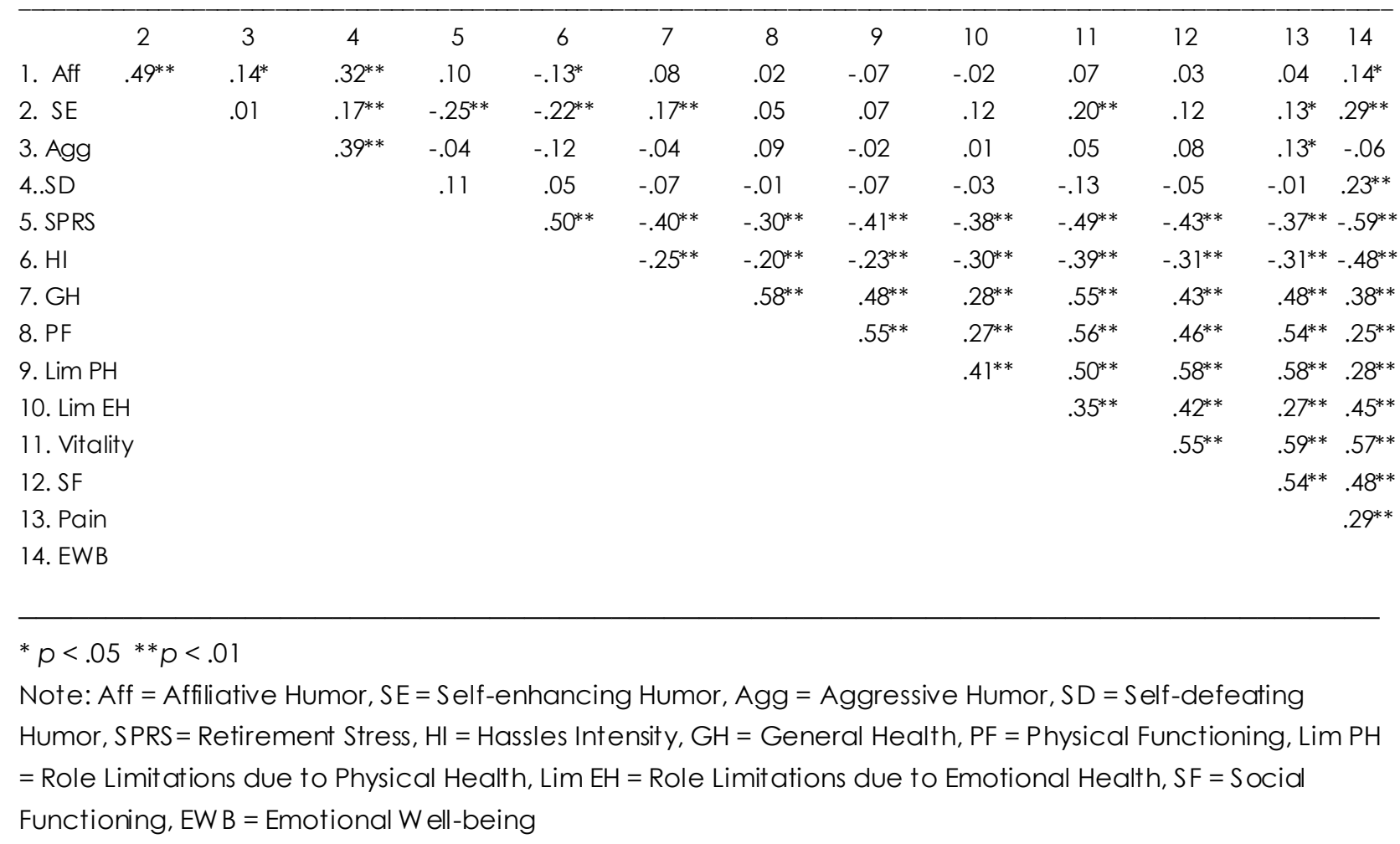

Table 2. Intercorrelations Between Subscales of Humor Styles, Stress, and Subscales of Health 
Examining the correlations between humor styles and health, both adaptive humor styles had positive correlations with some optimal health outcomes. Affiliative humor was positively correlated with Emotional Well-being only. However, Self-enhancing humor was positively correlated with General Health, Vitality, Pain, and Emotional Well-being. Self-defeating humor was negatively correlated with Emotional Wellbeing, as hypothesized. However, Aggressive humor had a significant positive correlation with Pain, which was not in the expected direction. This incongruity between expectations and outcomes for the Aggressive humor style will be elaborated upon in the Discussion.

All of the correlations between health outcomes and stress were significant, such that positive health outcomes were negatively correlated with stress and hassles intensity. These significant correlations demonstrate that there is indeed a strong relationship between health and stress and serve as a sturdy foundation on which to examine the moderating effects of humor.

Stress Moderating Effect of Humor

Regression analyses were used to examine the stress moderating effect of humor. Moderator effects were examined as interactions between either stress or life hassles and the moderating variables-the four humor styles (Aiken, L. S., \& West, 1991). For each of the eight health outcomes and for each of the four moderators, we assessed the main effects of stress (retirement stress or life hassles), the moderator, and their interaction. Only regressions for which significant interactions were found are described below, as these are the only instances in which a Humor Style was acting as a moderator between stress and he alth. For all regressions depicted in the Figures below, increasing scores on the y-axis represent optimal health outcomes.

Self-enhancing Humor as a Moderator

Hassles Intensity and Self-enhancing humor did not result in significant interactions across any health outcomes. Self-enhancing humor and Retirement Stress resulted in significant interactions for two health outcomes. Specifically, the regression of Emotional Well-Being on Retirement Stress at varying levels of Self-enhancing humor was significant $(F(3,257)=56.48, p<.001)$. The corresponding Retirement Stress $\times$ Self-enhancing interaction was significant, indicating a moderating effect $(\beta=.15, \mathrm{p}$ $<.01)$. In addition, the regression of Role Limitations due to Emotional Problems on Retirement Stress at differing levels of Self-enhancing humor was significant $(F(3,256)$ $=19.19, \mathrm{p}<.001)$. The corresponding interaction-Retirement Stress $\times$ Self-enhancing humor-was also significant $(\beta=.21, p<.001)$. 
As demonstrated in Figure 1, under low stress, reports of Emotional Well-Being were high and unaffected by humor style. However, when stress was high, retirees who reported high levels of Self-enhancing humor reported higher Emotional Well-Being than participants who reported low levels of Self-enhancing humor. This result supports the hypothesis that Self-enhancing humor would boost health scores, especially during periods of high stress. The regression of Role Limitations due to Emotional Problems at varying levels of Self-enhancing humor demonstrated a similar significant pattern.

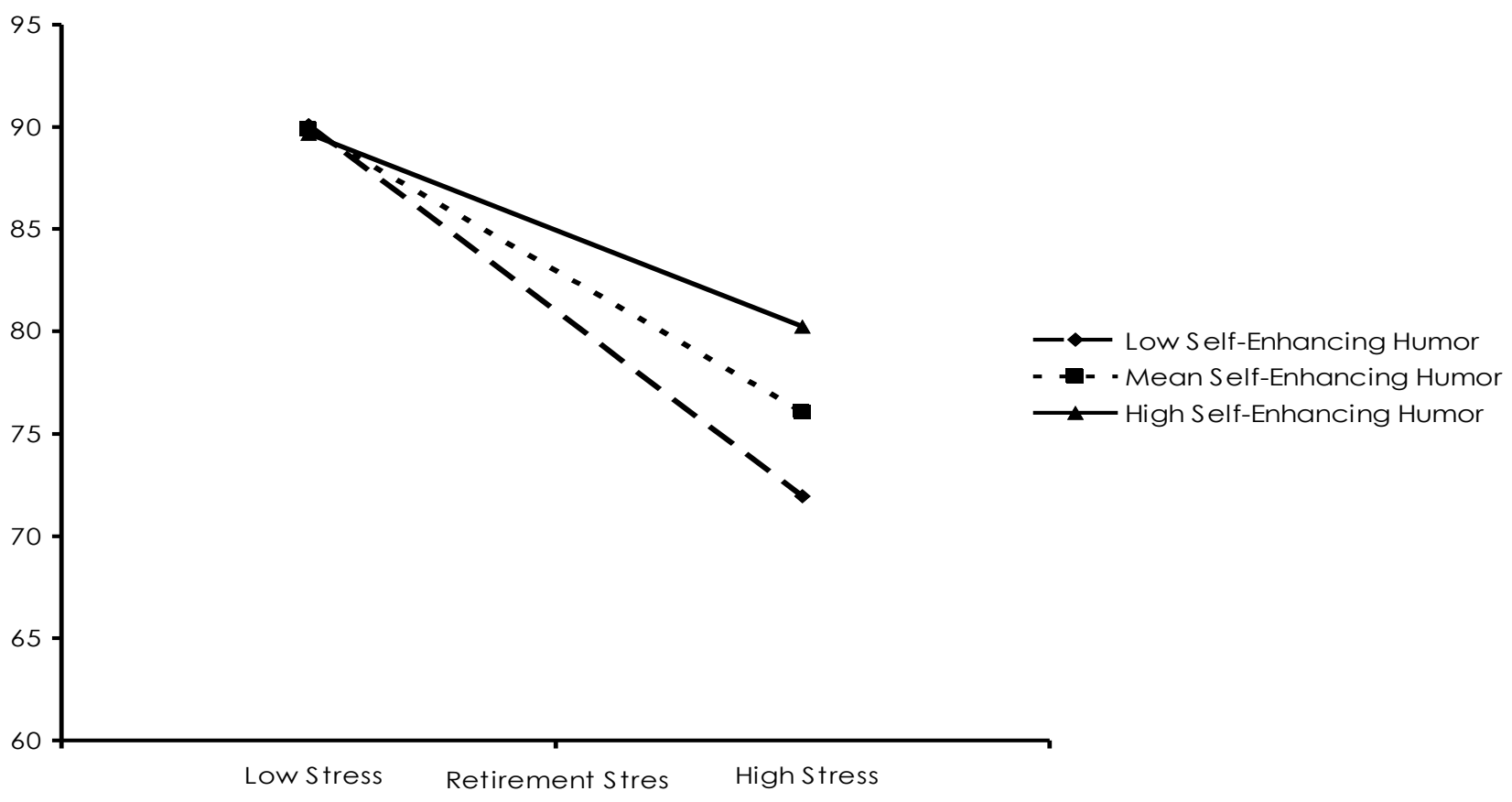

Figure 1. Regression lines predicting Emotional Wellbeing scores from Retirement Stress at varying levels of Self-enhancing humor

Affiliative Humor as a Moderator

Four interactions were found using Affiliative humor as a moderator between both Retirement Stress and Hassles Intensity and various health outcomes. Specifically, the regression of General Health on Retirement Stress at differing levels of Affiliative humor was significant $(F(3,257)=18.23, p<.001)$. The Retirement Stress $\times$ Affiliative humor interaction was significant, denoting a moderating effect, with $\beta=-.11$, $\mathrm{p}<$ .05. Additionally, the regression of Emotional Wellbeing on Hassles Intensity at differing levels of Affiliative humor was significant $(F(3,252)=28.98, p<.001)$. The corresponding Hassles Intensity $\times$ Affiliative humor interaction was significant $(\beta=-.16$, $p<.011$. Moreover, the regression of Social Functioning on Hassles Intensity at differing levels of Affiliative humor was significant $(F(3,252)=10.99, p<.001)$ and the 
interaction-Hassles Intensity $\times$ Affiliative humor-was significant $(\beta=-.14, p<.05)$. Finally, the regression of Role Limitations Due to Emotional Problems on Hassles Intensity at differing levels of Affiliative Humor was significant $(F(3,251)=10.71, p<$ $.001)$. The corresponding Hassles Intensity $\times$ Affiliative humor interaction was significant, $\beta=-.157, p<.05$.

Figure 2 shows that when hassles were low, retirees with high Affiliative humor did not appear to differ from those reporting low Affiliative humor. In high hassles situations, however, retirees with low Affiliative humor appeared to have less Role Limitations due to Emotional Problems. All four regressions, portraying Affiliative humor as a moderator, followed a similar pattern to that depicted in Figure 2.
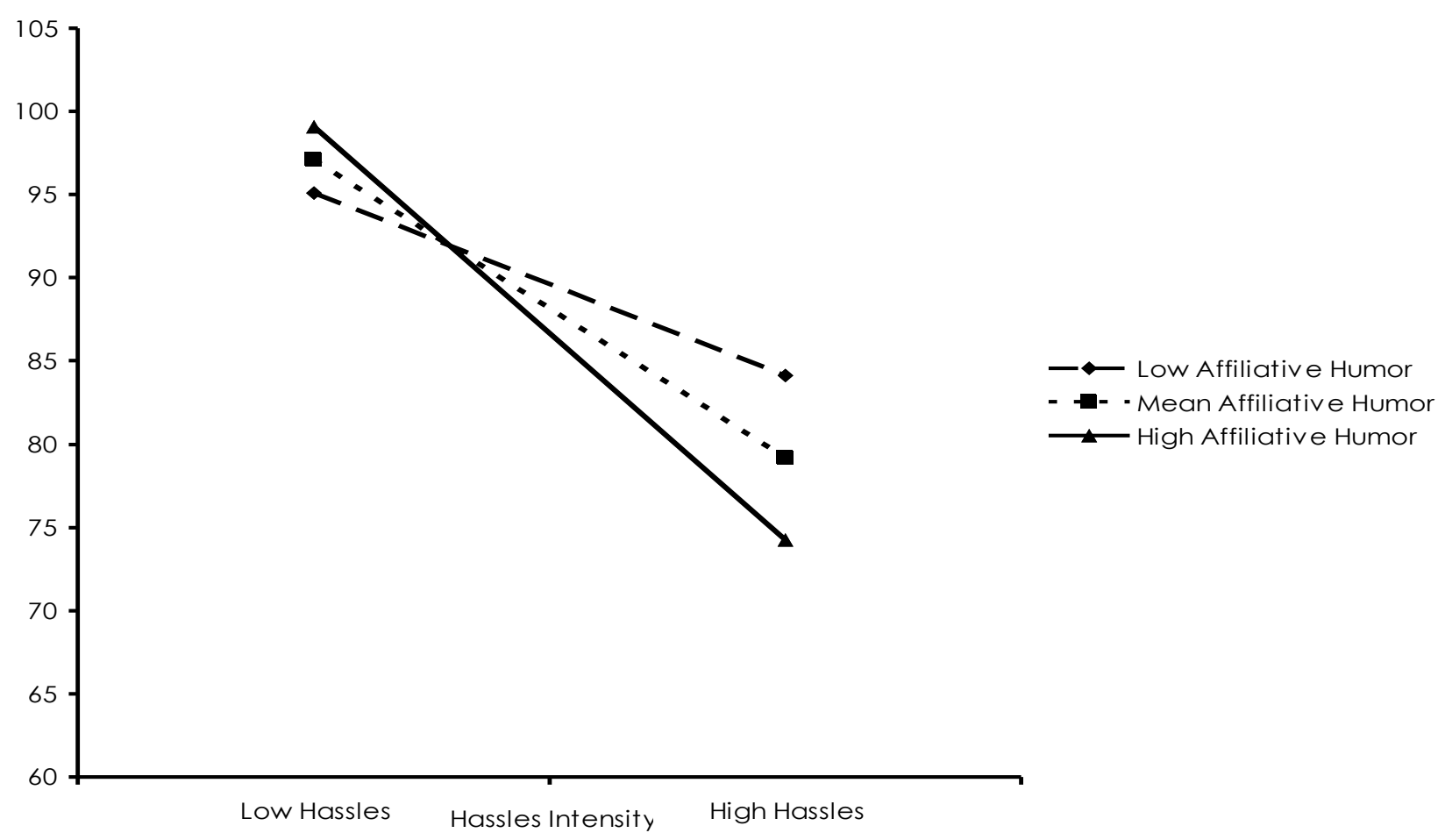

$\longrightarrow$ High Affiliative Humor

Figure 2. Regression lines predicting Role Limitations due to Emotional Problems scores from Hassles Intensity at varying levels of Affiliative humor

Self-defeating Humor as a Moderator

Turning now to the maladaptive humor styles, two significant interactions were revealed with Self-defeating humor as a moderator. The regression of Pain on Retirement Stress at differing levels of Self-defeating humor was significant $(F(3,256)$ $=15.66, p<.001)$. The corresponding Retirement Stress $\times$ Self-defeating humor interaction was also significant $(\beta=.13, p<.05)$. In addition, the regression of Pain on Hassles Intensity at differing levels of Self-defeating humor was significant $(F(3,252)=$ 10.70, $p<.001)$. The Hassles Intensity $\times$ Self-defeating humor interaction too was significant $(\beta=.14, p<.05)$. 
Plotted, the two significant regressions suggested that Self-defeating humor only appeared to be maladaptive when daily hassles/stress were low. However, when daily hassles/stress were high a higher Self-defeating score was related to less reported pain, and thus appeared to have an adaptive quality for retirees (see Figure 3).

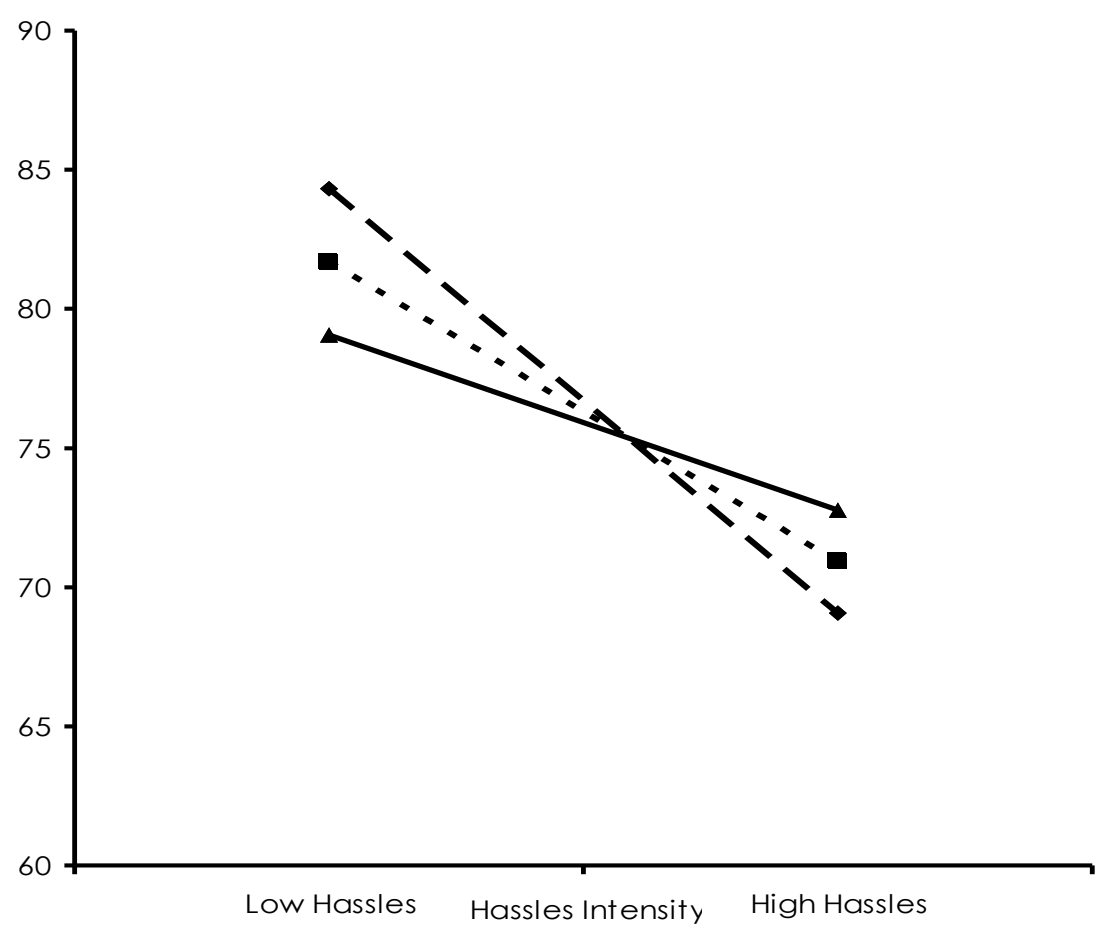

$\longrightarrow \bullet$ Low Self-Defeating Humor - - Mean Self-Defeating Humor $\longrightarrow$ High Self-Defeating Humor

Figure 3. Regression lines predicting Pain scores from Hassles Intensity at varying levels of Self-defeating humor

\section{Aggressive Humor as a Moderator}

Three significant interactions were discovered using Aggressive humor as a moderator. First, the regression of Energy/Vitality on Hassles Intensity at differing levels of Aggressive humor was significant $(F(3,253)=17.50, p<.001)$. The Hassles Intensity $\times$ Aggressive humor interaction was also significant at $\beta=.14, p<.05$. Additionally, the regression analysis of Pain on Hassles Intensity at differing levels of Aggressive humor was significant $(F(2,253)=12.72, p<.001)$. The Hassles Intensity $\times$ Aggressive humor interaction was significant at $\beta=.17, p<.01$. Finally, the regression of Pain along Retirement Stress at differing levels of Aggressive humor was significant ( $F$ ( 3 , $257)=17.92, p<.001$. The corresponding interaction of Retirement Stress $\times$ Aggressive humor was significant, $\beta=.14, p<.05$.

The three significant regressions depicting Aggressive humor as a moderator suggest that when hassles/stress was low, there did not appear to be a distinction between high and low Aggressive humor use. However, in contexts of high hassles/stress, 
higher use of Aggressive humor was related to more optimal health outcomes (see Figure 4).

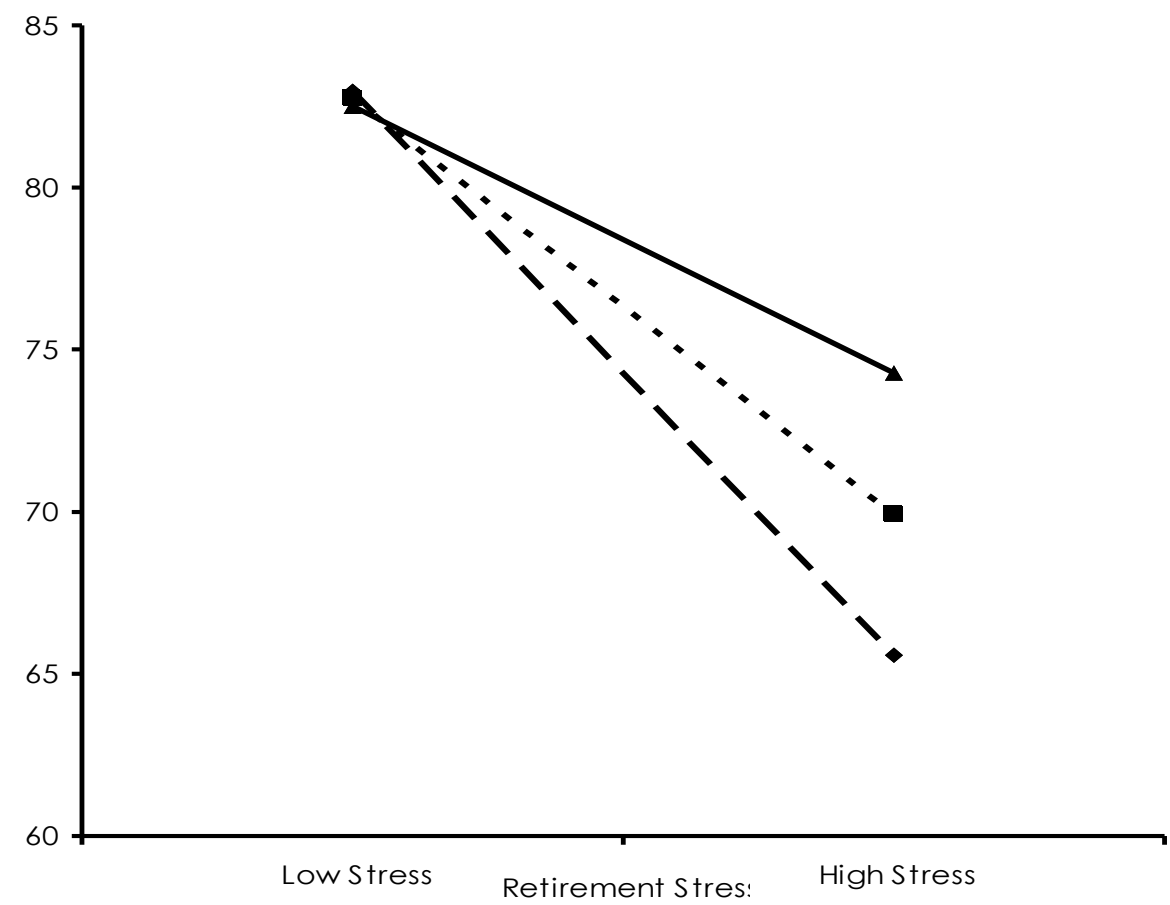

- Low Aggressive Humor - - - Mean Aggressive Humor $\longrightarrow$ High Aggressive Humor

Figure 4. Regression lines predicting Pain scores from Retirement Stress at varying levels of Aggressive humor

\section{Gender Differences}

Statistical examination of the sample demonstrated that the extent to which a humor style was adaptive depended on the stress context in which it was examined. As other contexts might result in similar patterns, we then examined whether gender, a dispositional factor, also affected the stress moderating effect of humor.

Initial Analysis of Gender Differences

Independent $t$-tests were used to examine gender differences on humor, stress, and heatlh outcomes. Refer to Table 1 for corresponding means and standard deviations.

A significant difference was found in the use of Aggressive humor $(t(261)=7.49, p<$ $.001)$, with means for males higher than means for females. There was also a significant difference in Self-defeating humor ( $t(260)=-2.90, p=.004)$, with means for males again exceeding means for females. Unexpectedly, significant gender differences were found with use of Affiliative humor as well $(t(260)=2.44, p<.05)$, 
with means for males higher than means for females. No gender differences were found for the use of Self-enhancing humor.

Gender differences were found in the amount of retirement stress reported $(t(259)=$ $-2.60, p<.01$ ), with females reporting more distal stress than males. There were no gender differences found with Hassles Intensity.

Comparing males and females along the health outcomes, two significant differences were found. A significant difference was found in reported health on the Pain outcome ( $t(262)=2.46, p<.05)$, with males reporting more optimal health along this measure than females. A significant difference was also found for Emotional Wellbeing $(t(262)=2.05, p<.05)$, again with means for males exceeding means for females.

Humor as a moderator by gender

Regression analysis was used to examine the stress moderating effect of humor and gender. Gender was dummy coded and all scores were centered prior to testing the joint effect of three independent variables (hassles/stress, humor style, and gender) on the dependent variable (health outcome). In all three-way interactions, humor style (Z) and gender (W) were moderator variables of the relation between stress/hassles $(X)$ and health outcome (Y). The signific ance level of XWZ was set at $p$ $<$.05. There were no significant three-way interactions that included Self-enhancing humor or Affiliative humor as moderators. However, several significant regressions were uncovered when examining Self-defeating humor and gender as moderators and Aggressive humor and gender as moderators. With Self-defeating humor and gender as the moderators, regressions revealed five significant interactions. With Aggressive humor and gender as the moderators, three significant three-way interactions were revealed. For all eight significant regressions, male retirees followed the same trend reported in the aforementioned two-way regressions, such that Selfdefeating and Aggressive humor only appeared maladaptive when stress was low. However, when stress was high, higher Self-defeating and Aggressive humor scores were related to more optimal health outcomes, and thus appeared to have an adaptive quality for retirees. However, for female retirees, the opposite pattern emerged. When hassles/stress were low, humor levels had no impact on health outcomes. However, once hassles/stress were high, high Self-defeating and Aggressive humor scores were related to poorer health outcomes and appeared to be maladaptive (See Figure 5). 


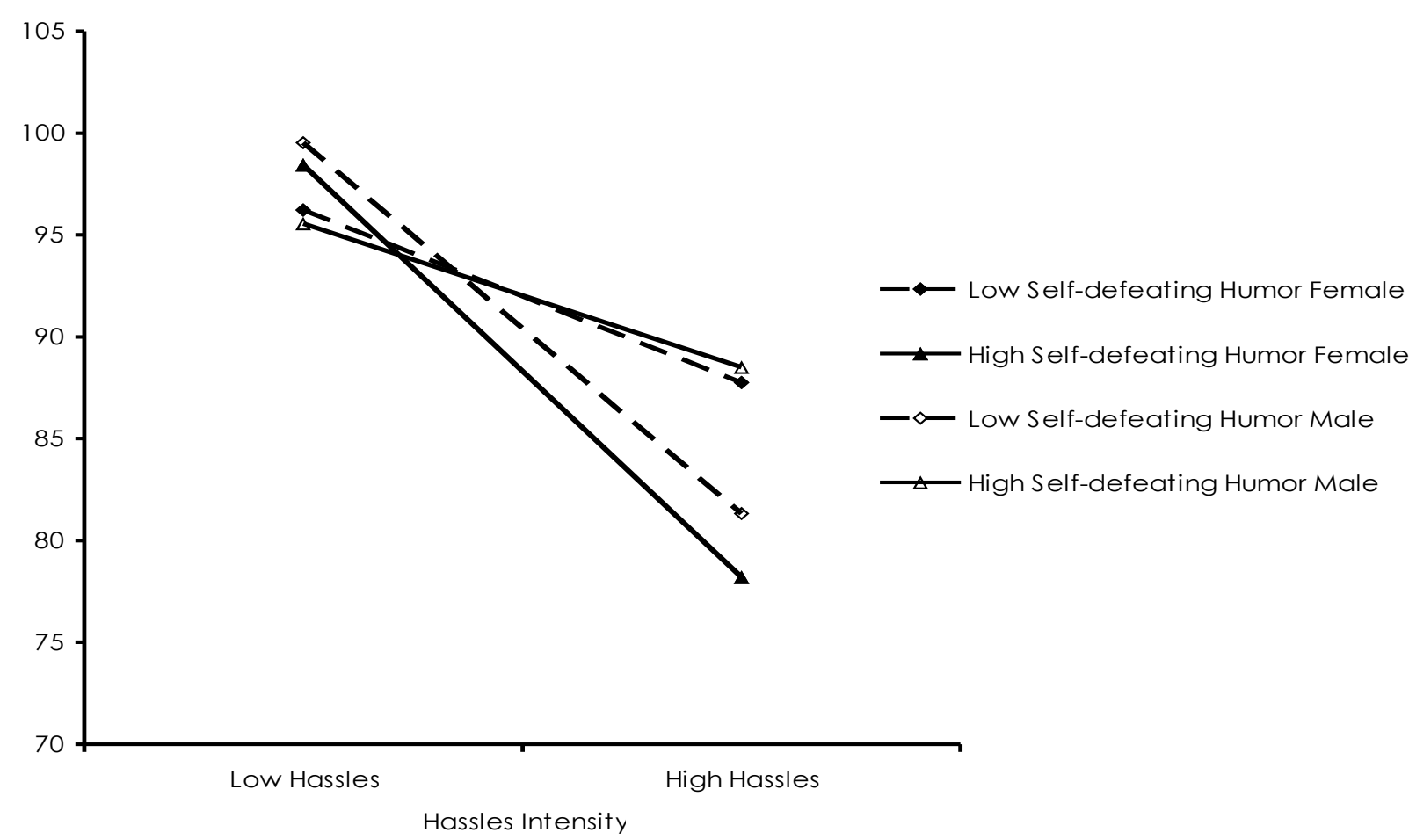

Figure 5. Regression lines predicting Social Functioning scores from Hassles Intensity at varying levels of Self-defeating humor and gender

By including gender as a moderator, the contextual nature of humor as a moderator is underscored. It appears that not only the level of stress and hassles determines the adaptiveness of a humor style, but gender as well.

\section{Discussion}

In this study we aimed to examine further the relationship between humor, stress and health in retirement. Analyses were aimed at understanding the moderating effect of humor on the relationship between stress and measures of health.

\section{Humor as a Moderator}

The plotted two-way interactions suggest that the "adaptiveness" of humor styles depends on the level (low or high) of stress or hassles one perceives. These results suggest that it may not be adequate to label a humor style as simply adaptive or maladaptive. It was found that Self-enhancing humor only appears to be truly adaptive in situations of high stress. In low stress situations, however, retirees with high Self-enhancing humor did not appear to differ from those reporting low Selfenhancing humor. In this way, the adaptiveness of the humor style appears to be contextual. Perhaps under sufficiently low stress there is no advantage to be gained via Self Enhancing Humor, but under high stress the adaptive advantage is revealed. 
Similarly, when examining the two-way interactions, Self-defeating humor appeared only maladaptive when daily hassles are low. However, when daily hassles were high a higher Self-defeating score was related to less Pain, and thus appeared to have an adaptive quality. This was a consistent pattern when examining the Aggressive humor style as well. Thus, it seems that the extent to which Self-defeating and Aggressive humor are maladaptive is truly situational.

The three-way interaction analyses revealed a dispositional variable that affects the adaptiveness of a humor style-gender. Examination of the significant three-way interactions demonstrated a consistent pattern of divergence between males and females across multiple health outcomes, underscoring the importance of examining gender when exploring adaptiveness in the use of humor. Males followed the pattern revealed in the two-way interactions, such that a high Self-defeating or Aggressive humor score was adaptive during high stress/hassles. Females, on the other hand, displayed the hypothesized pattern, such that a high Self-defeating or Aggressive humor score was more maladaptive when stress/hassles were high.

These results call attention to the importance of examining both contextual and person variables before labeling a humor style as "adaptive" or "maladaptive." It may be that something as basic as gender might indicate the extent to which a humor style serves as an adaptive or maladaptive mechanism when dealing with stress and health in particular circumstances. Perhaps age is another such relevant person variable.

These findings have interesting implic ations for the HSQ (Martin et al., 2003). The HSQ is a constructive acknowledgement that humor is not a unitary construct, but multifaceted, including positive and adaptive, as well as negative and maladaptive styles. However, the results of the present research imply that even the addition of positive and negative humor styles is not a sufficient acknowledgement of humor's complexity. It appears that the adaptiveness of the humor styles may not be an allor-none phenomenon, but that adaptiveness or maladaptiveness of a given style may be a function of both contextual (e.g., high or low stress) and dispositional variables (e.g., gender). However, it should be kept in mind that this sample of retirees is comprised of well-educated college graduates from the same undergraduate institution. Future research should attempt to collect a more diverse sample to see if these results will be replicated. Moreover, further understanding of the contextual nature of the adaptiveness of humor styles may benefit from looking at different contexts. In this study daily hassles and stress were examined, but it may 
be that differing levels of self-esteem or anxiety also produce similar patterns that highlight the contextual nature of the humor styles.

Examining these moderation effects not only revealed information about humor as a moderating variable, but intimates information about the general nature of these humor styles as well. For instance, in examination of Figure 2, Affiliative humor appeared to be a more natural humor style in a low stress context. This humor style is consistently, and signific antly, positively associated with cheerfulness, psychological wellbeing, and social intimacy (Martin et al., 2003), as well as harmony, sharing, and mutual happiness among in-group members (Kazarian \& Martin, 2004). So while this humor style may be adaptive in terms of enhancing social supports and relationships, it does not appear to be as effective in terms of directly coping with stress or health. Further investigation of situations that require adaptation, other than health, may further our understanding of the adaptiveness of Affiliative humor.

Taking a broader look at the moderating effects of the negative humor styles, it could be argued that the use of Self-defeating and Aggressive humor styles may just be an acknowledgement of one's circumstances under high stress or high hassles (see Figures 3 and 4). In this way, the difference between high and low use of the negative humor styles during high stress situations may reflect a tendency to express or communicate feelings and awareness of discomfort as opposed to a tendency to suffer in silence. It may be that the communic ation of discomfort, although negative towards others (Aggressive humor) or oneself (Self-defeating), may be cathartic because the individual is simply expressing that there is a problem. Indeed, actively suppressing one's negative emotional experience has been related to the development of health problems (Pennebaker, 1992). Whereas Self-enhancing humor is adaptive because one is cognitively reappraising a stressful situation, the adaptiveness of the negative styles may function in a different way-by merely acknowledging or confronting a negative circumstance via humor.

As always, it is a concern with correlational data that causality cannot be demonstrated, but if the relationship is causal, it may not be clear which variable is the cause and which is the effect. The present study proposes that changes in health outcomes in reaction to stress may be alleviated or exacerbated by the use of humor. This study is a partial replication of Nezu and colleagues (1988). Going beyond the correlational methodology used in the present study, Nezu et al. (1988) used a more rigorous prospective design to test this relationship. They reported finding humor as a moderator between stressful events and depressive symptoms (Nezu et al., 1988). Similarly, the present study found more significant results with mental health measures than the truly physic al ones. 
Interpreting Unexpected Correlations

Correlations that have not been previously reported were revealed with this current sample. First, the Aggressive humor style had a significant positive correlation with Pain, contrary to expectations for a negative correlation with the health measures. On the other hand, Self-defeating humor, the other negative humor style, had an expected negative correlation with the health measures.

The moderating effect of Aggressive humor supported the positive correlation. Reports of high use of Aggressive humor appeared to be more adaptive in periods of high stress in both the combined sample and among males. However, this effect may not be entirely satisfying as an explanation. The Self-defeating humor style was negatively correlated with Emotional Wellbeing, as expected, and among the combined sample and males, appeared to have the same adaptive quality in high stress/hassles as Aggressive humor. Although the unexpected positive correlation between Aggressive humor and Pain seems to be indicative of a genuine moderating effect and not a mere anomaly, future research may clarify this finding.

An unpredicted significant gender difference with use of Affiliative humor was also revealed, as males reported more use of Affiliative humor than females. To our knowledge this has not been reported in previous studies using the HSQ. A brief inquiry into previous literature has revealed two common outcomes regarding gender differences on the HSQ. The most common finding is that males use the Selfdefeating and Aggressive humor styles more than females, but no significant gender differences emerged with the Self-enhancing and Affiliative humor styles (Kazarian \& Martin, 2004; Martin et al., 2003). Otherwise, studies indicate that there are no gender differences across all four humor styles (Erickson \& Feldstein; Martin \& Lefcourt, 1983).

It is not entirely clear why in the current sample gender differences were found with respect to the Affiliative humor measure. It is worth mentioning that the studies mentioned above utilized mostly college-aged samples. It may be that elderly males typically use more Affiliative humor, or this finding may be unique to this sample. Further research should be done to examine the use of humor among diverse elderly samples to clarify this unexpected outcome.

Limitations and Future Directions

One limitation of this study is that stress measures were collected at a single time point. The use of ecological momentary assessments (EMAs), in which participants 
are reminded throughout the day to record immediate experiences, may reveal more information on proximal stress in particular. Previous studies have found that elderly individuals do not report as many hassles as younger adults (Aldwin, Sutton, Chiara, \& Spiro, 1996). Perhaps it may be more difficult for older individuals to recall hassles retrospectively. It has also been suggested that the number of hassles decrease as the number of social roles decrease in old age (Aldwin et al., 2007). Alternatively, hassles from other sources, such as diminishing abilities and loss of acquaintances may increase for the elderly.

Likewise, Gottlieb and Wolfe (2002) promote study designs that facilitate observation of coping as it unfolds over time. Again the use of EMAs could prompt real-time assessment of the use of humor as a coping strategy in conjunction with hassle and stress reports. A study utilizing EMA could then illuminate both real-time stress as well as the strategies used to cope with them.

Finally, these results should only be generalized to a very well-educated, Caucasian, elderly retired population. The current research pulled from an email listing of college graduates. More than $60 \%$ of this sample acquired additional education beyond a four-year college degree. In addition, the retirees that comprised the current sample were all comfortable enough with computers to complete a lengthy 45 minute online-survey. It appears that this unique sample may not need to rely as much on humor when dealing with stress. Highly educated, wealthy individuals tend to be buffered from negative life experiences (Baltes \& Lang, 1997) and may have a wealth of other coping strategies to choose from. This is plausible, given that humor is an emotional coping strategy, which makes the best of a stress one cannot change. Future studies could examine these humor styles in relation to stress among other, more diverse samples.

Given some prominent aspects of humor, there is sound justification for more extensive research effort which addresses some of the complexity of the roles and effects of humor in retirement. First, the fact that humor is a form of emotional coping (Folkmann \& Lazarus, 1988), may imply a critical role as a coping response in retirement. Emotional coping consists of making the best of a situation in which problem solving to eliminate the stress is not an option, and in retirement many stressors, such as decreases in physical abilities or loss of friends, are such sources of unavoidable stress. Consequently, a humorous perspective may often be significantly helpful in minimizing the negative consequences of such losses. Additionally, the cognitive flexibility implicit in being able to readily switch from a telic or goal directed state of mind to a paratelic or playful state may be beneficial in itself (Apter, 1997). Further, the social nature and consequences of humor can also 
have particular relevance in retirement. Since social support is a prominent buffer against stress vulnerability (Koenig, Westlund, George, Hughes, Blazer, \& Hybels, 1993), humor can be seen as one means of fostering and maintaining positive and supportive social relationships. These are just a few of the potential reasons why there may be particular value in devoting extensive future research effort to a better understanding of roles of humor in the context of retirement.

Finally, this line of research-investigating the stress and health buffering capacity of different humor styles-was also designed to set the groundwork for more applied research designs in the future. For example, as adaptive consequences of differing humor styles are clarified in different contexts, future studies may test the feasibility of teaching coping humor to retirees for whom it is low or to reinforce coping humor in individuals who may use this style only in select instances. A previous study has shown that humor can be used to alter an emotional response in a therapeutic context (Ventis, Higbee, \& Murdock, 2001). Ventis and colleagues found that humor can be effectiv ely used to desensitize phobias and reevaluate a fear. The findings of Ventis and colleagues may have implications for the development of retirement transition groups designed to help individuals reassess affective response using humor. If humor can be introduced to reduce fear, it may be that humor can also be introduced to help relieve stress and help retirees reappraise daily life hassles as well.

\section{References}

Aldwin, C. M., Sutton, K. J., Chiara, G., \& Spiro A. III. (1996). Age differences in stress, coping, and appraisal: Findings from the Normative Aging Study. Journals of Gerontology: Psychological Sciences and Social Sciences, Series B, 51, 179-188.

Aiken, L. S., \& West, S. G. (1991). Multiple regression: Testing and interpreting interactions. Newbury Park: Sage.

Aldwin, C. M., Yancura, L. A., \& Boeninger, D. K. (2007). Coping, health, and aging. In C. M. Aldwin, C. L. Park, \& A. Spiro, III. (Eds.), Handbook of health psychology and aging (pp. 210-226). New York: Guilford.

Anderson, C. A., \& Arnoult, L. H. (1989). An examination of perceived control, humor, irrational beliefs, and positive stress as moderators of the relation between negative stress and health. Basic and Applied Social Psychology, 10(2), 101-117.

Apter, M. (1997). Reversal theory: What is it? The Psychologist, 10(3), 217-220. 
Arber, S., \& Cooper, H. (1999). Gender differences in health in later life: The new paradox. Social Science \& Medicine, 48, 61-76.

Argyle, M. (1997). Is happiness a cause of health? Psychology and Health, 12, 769-781.

Baltes, M. M., \& Lang, F. R. (1997). Everyday functioning and successful aging: The impact of resources. Psychology \& Aging, 12, 433-443.

Beehr, T. A., \& Adams, G. A. (2003). Introduction and overview of current research and thnking on retirement. In G. A. Adams \& T A. Beehr (Eds.), Retirement: Reasons, processes, and results (pp. 1-5). New York: Springer.

Berk, R. A. (2001). The active ingredients in humor: Psychophysiological benefits and risks for older adults. Educational Gerontology, 27, 232-339.

Boyle, G. J., \& Joss-Reid, J. M. (2004). Relationship of humour to health: A psychometric investigation. British Journal of Health Psychology, 9, 51-66.

Carver, C. S., Scheier, M. F., \& Weintraub, J. K. (1989). Assessing coping strategies: A theoretically based approach. Journal of Personality and Social Psychology, 56 (2), 267283.

Celso, B. G., Ebener, D. J., \& Burkhead, E. J. (2003). Humor coping, health status, and life satisfaction among older adults residing in assisted living facilities. Aging \& Mental Health, $7(6), 438-445$.

Cohen, S., Janicki-Deverts, D., \& Miller E. (2007). Psychological stress and disease. Journal of the American Medical Association, 298, 1685-1687.

Delongis, A., Coyne, J. C., Dakof, G., Folkman, S., \& Lazarus, R. S. (1982). Relationship of daily hassles, uplifts, and major life events to health status. Health Psychology, 1, 119-136.

DeLongis, A., Folkman, S., \& Lazarus, R. S. (1988). The impact of daily stress on health and mood: Psychological and social resources as moderators. Journal of Personality and Social Psychology, 54, 486-495.

Edwards, J. R., \& Cooper, C. L. (1988). The impacts of positive psychological states on physical health: A review and theoretical framework. Social Science \& Medicine, 27, 1447-1459. 
Erickson, S. J., \& Feldstein, S. W. (2007). Adolescent humor and its relationship to coping, defense strategies, psychological distress, and well-being. Journal of Child Psychiatry and Human Development, 37, 255-271.

Folkman, S., \& Lazarus, R. S. (1988). Coping as a mediator of emotion. Journal of Personality and Social Psychology, 54 (3), 466-475.

Folkman, S., Lazarus, R. S., Pimley, S., \& Novacek, J. (1987). Age differences in stress and coping process. Psychology \& Aging, 2, 171-184.

Freeman, G. P., \& Ventis, W. L. (2008, November). Gender differences in the use of humor as a coping mechanism on retirement stress and daily hassles. Poster session presented at The Gerontological Society of America's 61 st Annual Scientific Meeting, National Harbor, MD.

Gottlieb, B. H., \& Wolfe, J. (2002). Coping with family caregiving to persons with dementia: A critical review. Aging and Mental Health, 6, 325-342.

Gunnar, M., \& Quevedo, K. (2007). The neurobiology of stress and development. Annual Review of Psychology, 58, 145-73.

Hays, R. D., Sherbourne, C. D., \& Mazel, R. M. (1993). The RAND 36-I tem Health Survey 1.0. Health Economics, 2, 217-227.

Hayslip, B. Jr., Beyerlein, M., \& Nichols, J. A. (1997). Assessing anxiety about retirement: The Case of Academicians. International Journal of Aging and Human Development, $44(1), 15-36$.

Kanner, A. D., Coyne, J. C., Schaefer, C., \& Lazarus, R. S. (1981). Comparison of two modes of stress measurement: Daily hassles and uplifts versus major life events. Journal of Behavioral Medicine, 4(1), 1-39.

Kazarian, S. S., \& Martin, R. M. (2004). Humour styles, personality, and well-being among Lebanese university students. European Journal of Personality, 18, 209-219.

Kelly, M., \& Barratt, G. (2007). Retirement: Phantasy and reality_Dying in the saddle or facing up to it? Psychodynamic Practice, 13(2), 197-202.

Kessler, R. C., \& McLeod, J. D. (1984). Sex differences in vulnerability to undesirable life events, American Sociological Review, 49, 620-631. 
Kirsh, G. A., \& Kuiper, N. A. (2003). Positive and negative aspects of sense of humor: Associations with the constructs of individualism and relatedness. Humor: International Journal of Humor Research, 16(1), 33-62.

Koenig, H., Westlund, R., George, L., Hughes, D., Blazer, D., \& Hybels, C. (1993). Abbreviating the Duke Social Support Index for use in chronically ill elderly individuals. Psychosomatics: Journal of Consultation Liaison Psychiatry, 34(1), 61-69.

Kuiper, N. A., Grimshaw, M., Leite, C., \& Kirsh, G. (2004). Humor is not always the best medicine: Specific components of sense of humor and psychological well-being. Humor: International Journal of Humor Research, 17(1), 135-168.

Kuiper, N. A., Martin, R. A., \& Olinger, L. J. (1993). Coping humour, stress, and cognitive appraisals. Canadian Journal of Behavioral Science, 25(1), 81-96.

Lee, C. (2001). Experiences of family caregiving among older Australian women. Journal of Health Psychology, 6, 393-404.

Lefcourt, H. M., Davidson, K., Shepherd, R., Phillips, M. Prkachin, K., \& Mills, D. (1995). Perspective-taking humor: Accounting for stress moderation. Journal of Social and Clinical Psychology, 14, 373-391.

Marshall, V. W., Clarke, P. J., \& Ballantyne, P. J. (2001). Instability in the retirement transition: Effects on health and well-being in a Canadian study. Research on Aging, 23(4), 379-409.

Martin, R. A. (2001). Humor, laughter, and physical health: Methodological issues and research findings. Psychological Bulletin, 127(4), 504-519.

Martin, R. A. (2004). Sense of humor and physical health: Theoretical issues, recent findings, and future directions. Humor: International Journal of Humor Research, 17(1), 119.

Martin, R. A. (2007). Personality approaches to the sense of humor. In The psychology of humor: An integrative approach. Amsterdam, Netherlands: Elsevier.

Martin, R. A., Kuiper, N. A., Olinger, L. J., \& Dance, K. A. (1993). Humor, coping with stress, self-concept, and psychological well-being. Humor: International Journal of Humor Research, 6, 89-104.

Martin, R. A., \& Lefcourt, H. M. (1983). Sense of humor as a moderator of the relations between stressors and moods. Journal of Personality and Social Psychology, 45, 13131324. 
Martin, R. A., Puhlik-Doris, P., Larsen, G., Gray, J., \& Weir, K. (2003). Individual differences in uses of humor and their relation to psychological well-being: Development of the humor styles questionnaire. Journal of Research in Personality, 37(1), 48-75.

Matud, M. P. (2004). Gender differences in stress and coping styles. Personality and Individual Differences, 37, 1401-1415.

McDonough, P., \& Walters, W. (2001). Gender and health: Reassessing patterns and explanations. Social Science \& Medicine, 52, 547-559.

Miller, G. E., Chen, E., \& Zhou, E. S. (2007). If it goes up, must it come down? Chronic stress and the hypothalamic-pituitary-adrenocortical axis in humans. Psychological Bulletin, 133, 25-45.

Nezu, A. M., Nezu, C. M., \& Blissett, S. E. (1988). Sense of humor as a moderator of the relation between stressful events and psychological distress: A prospective analysis. Journal of Personality and Social Psychology, 54 (3), 520-525.

Orfila, F., Ferrer, M., Lamarca, R., Tebe, C., Domingo-Salvany, A., \& Alonso, J. (2006). Gender differences in health-related quality of life among the elderly: The role of objective functional capacity and chronic condition. Social Science \& Medicine, 63, 2367-2380.

Pennebaker, J. W. (1992). Inhibition as the linchpin of health. In H. S. Friedman (Ed.), Hostility, coping, and health (pp. 127-139). Washington, DC: American Psychological Association.

Pinquart, M., \& Schindler, I. S. (2007). Changes of life satisfaction in the transition to retirement: A latent-class approach. Psychology and Aging, 22 (3), 442-455.

Porterfield, A. L. (1987). Does sense of humor moderate the impact of life stress on psychological and physical well-being? Journal of Research in Personality, 21 , 306-317.

Rowlison, R. T., \& Felner, R. D. (!988). Major life events, hassles, and adaptation in adolescence: Confounding in the conceptualization and measurement of life stress and adjustment revisited. Journal of Personality and Social Psychology, 55, 432-444.

Sapolsky, R. M. (2004). Organismal stress and telomeric aging: An unexpected connection. Proceedings of the National Academy of Sciences of the United States of America, 101, 17323-17324. 
Sharpley, C. F. (1997). Psychometric properties of the self-perceived stress in retirement scale. Psychological Reports, 81, 319-322.

Thorson, J. A., \& Powell, F. C. (1993). Development and validation of a multidimensional sense of humor. Journal of Clinical Psychology, 49, 13-23.

Tümkaya, S. (2007). Burnout and humor relationship among university lecturers. Humor: International Journal of Humor Research, 20(1), 73-92.

Ventis, W. L., Higbee, G., \& Murdock, S. A. (2001). Using humor in systematic desensitization to reduce fear. Journal of General Psychology, 128(2), 241-253.

Wang, M. (2007). Profiling retirees in the retirement transition and adjustment process: Examining the longitudinal change patterns of retirees' psychological well-being. Journal of Applied Psychology, 92 (2), 455-474.

World Health Organization (WHO). (2000). Women, ageing and health. Fact sheet no. 252.

\section{About the authors:}

Gillian P. Freeman conducted the above research while completing her M.A. in psychology at The College of William \& Mary. She is continuing her graduate education at the University of Massachusetts Amherst in Developmental Psychology, with a focus on aging, retirement, and humor.

Address for correspondence: G. P. Freeman, Department of Psychology, University of Massachusetts Amherst, Tobin Hall, 135 Hicks Way, Amherst, MA, 01003-9271, United States of America

E-mail: gpfreema@psych.umass.edu

W. Larry Ventis is a clinical psychologist and Professor at the College of William and Mary. His research on humor has dealt primarily with applications of humor. The current topic was of particular interest as he is not so far from retirement himself. 